\title{
A INOVAÇÃO NOS ESTUDOS SOBRE HIATO TECNOLÓGICO: Uma Revisão Crítica da Literatura
}

Sidnei de Caria Junior

\section{Introdução}

\begin{abstract}
"As a matter of fact, capitalist economy is not and cannot be stationary. Nor is it merely expanding in a steady manner. It is incessantly being revolutionized from within by new enterprise, i.e., by the intrusion of new commodities or new methods of production or new commercial opportunities into the industrial structure as it exists at any moment. Any existing structures and all the conditions of doing business are always in a process of change. Every situation is being upset before it has had time to work itself out. Economic progress, in a capitalist society, means turmoil." (Schumpeter, 1942, p.32)
\end{abstract}

Durante as últimas seis décadas, economistas têm buscado entender como os países crescem e se desenvolvem dentro do sistema capitalista. Esse objetivo em comum nunca quis dizer, porém, que métodos de abordagem fossem similares ou que tenha havido algum consenso sobre como se entender o método de produção capitalista.

O trabalho seminal de Solow (1956) acabou sendo a fonte de um leque de estudos que creditavam o crescimento econômico a uma série de fatores exógenos aos países, entre eles a tecnologia utilizada em suas matrizes produtivas. No entanto, após duas décadas de relativa estabilidade no entendimento dos determinantes da mudança econômica, a década de 1980 marcou o reavivamento dos estudos sobre o crescimento, com uma mudança, ainda que parcial, na perspectiva mainstream. Essa mudança se dá, principalmente, pela atribuição do crescimento econômico a fatores endógenos ao sistema, e não mais a fatores externos que afetam as economias nacionais, com a mudança técnica endógena como determinante primordial deste processo (PORCILE et al., 1999).

Gradativamente, deixou de ser considerado nestes novos modelos endógenos de crescimento, além da mudança técnica exógena, o tratamento da disponibilidade de oportunidades tecnológicas como homogênea a todos os países, como se a tecnologia fosse um bem "público" e acessível a todos. Contribuiu para essa reconsideração de premissas, alguns fatos observados ao longo do tempo e praticamente indiscutíveis: o aumento contínuo da produtividade do trabalho e da renda per capita; a divergência nas taxas de crescimento dos diferentes países, e a mobilidade de fatores de produção e diferenciais na remuneração desses fatores (PORCILE et al, 1999).

Verificou-se entre as décadas de 50 e 80 o que Schumpeter já afirmava nos idos de 1940, e destacado na citação que abre esta introdução: o sistema é revolucionado por dentro a todo momento, e não por forças externas, tal como defendiam economistas atados às premissas da Escola Neoclássica. As condições não estão “dadas” nem são, muito menos, estáveis - elas mudam antes mesmo que possam se estabelecer por completo.

Esse interesse na mudança endógena não reacendeu a discussão apenas internamente ao mainstream. Ora, a mudança técnica pode estar de fato no centro do crescimento endógeno, mas deve haver alguma força que promova a própria mudança técnica - força essa descrita por Schumpeter como inovação, a responsável pelos novos produtos, métodos de produção e oportunidades de mercado introduzidos ao sistema a todo momento e motivadores da sua constante evolução e revolução. Neste sentido, inspirada pelo ideal Schumpeteriano de inovação endógena, a Escola Evolucionária é inaugurada no início da década de 1980 por Richard Nelson e Sidney Winter, com sua abordagem que coloca no centro da mudança econômica os processos concorrenciais de agentes heterogêneos, acontecendo em nível microeconômico movidos pelo conhecimento, pela inovação e por retornos crescentes, valendo-se de analogia aos processos evolutivos biológicos para descrever e entender o sistema capitalista.

A própria literatura sobre hiato tecnológico, enquanto converge sobre uma das causas das diferenças entre as taxas de crescimento dos países - a mudança técnica endógena - diverge na

\footnotetext{
${ }^{1}$ Negrito adicionado.
} 
abordagem do problema. São utilizados com frequência modelos econométricos aplicados a dados agregados, formando proxies que podem não ser as mais adequadas para entender um fenômeno microeconômico, como no caso recorrente do uso da renda per capita como variável representativa da distância tecnológica entra países.

O presente trabalho intenta apresentar uma revisão crítica da bibliografia internacional e, principalmente, nacional sobre Hiato Tecnológico, buscando apontar lacunas a serem exploradas e caminhos para atendê-las, à luz da Teoria Evolucionária Neo-Schumpeteriana. Será que se trata o progresso tecnológico e a inovação corretamente a partir de suas características? Como isso tem sido feito ao longo do tempo dentro e fora do Brasil? Há padrões nos resultados, apesar das diferentes técnicas e abordagens?

Para tanto, está divido em três seções: a primeira tratará da evolução no tratamento do tema na literatura internacional, a partir dos anos 1950; a segunda trará uma revisão da literatura nacional, apresentando os diferentes modos que os estudiosos brasileiros abordam a defasagem tecnológica e algumas convergências em seus resultados.

A terceira e última parte tratará da imprescindibilidade da inserção de proxies que busquem representar a inovação e os esforços inovativos das firmas em estudos sobre Hiato Tecnológico caso deseje-se (a) representar corretamente a força motriz da mudança tecnológica; (b) analisar a mudança tecnológica no nível econômico em que ela de fato acontece; (c) encontrar causas para as diferenças no progresso tecnológico dos países; (d) entender como as firmas de um determinado setor de determinado país concorrem entre si e internacionalmente. Finalmente nesta seção, ainda que não seja o objetivo primário deste trabalho, apresenta-se uma direção para a qual os recentes estudos sobre os esforços brasileiros para inovar e as políticas governamentais de incentivo à inovação parecem estar apontando, além do já consensual baixo dinamismo inovativo da indústria de transformação do Brasil: atividades caracterizadoras de difusão tecnológica sendo consideradas como inovação stricto sensu.

\section{Inovação e Hiato Tecnológico na literatura estrangeira}

Entre os anos de 1950 e 1960, a ideia de que o desenvolvimento científico era condição inicial essencial para qualquer progresso técnico e econômico tinha sua legitimidade ilustrada pelo início da mensuração sistemática dos esforços nacionais de pesquisa e desenvolvimento pelos países da OCDE, já em 1963, ano do lançamento da primeira edição do Manual Frascati ${ }^{2}$. Nessa época, o grau de densidade tecnológica dos produtos se tornaria uma das formas mais amplamente aceitas de categorizar o comércio internacional. Autores como Posner (1961) e Linder (1961) mostravam que as inovações tecnológicas ditavam o comércio intra e internacional, sugerindo que vantagens comparativas deveriam ser construídas, inclusive mediante intervenção estatal (ERBER, 2010).

No entanto, enquanto entre os estudiosos do comércio a importância do avanço técnico era ideia predominante, o programa neoclássico de pesquisa em economia ainda relutava em considerar o progresso tecnológico como fator determinante do crescimento, ao contrário dos teorias e modelos neoKeynesianos elaborados logo antes e depois da Segunda Guerra Mundial, tais como os de Harrod (1939) e Domar (1946), que carregavam a crença da época de que o mercado, sozinho, não era capaz de promover crescimento e pleno emprego. O próprio modelo proposto por Solow, em 1956, imbuído das hipótesespadrão do programa de pesquisa neoclássico ${ }^{3}$, apesar de considerar o progresso técnico como exógeno, admitia que seu termo de erro incorporava fatores determinantes para a promoção do crescimento sendo que, dentre eles, estaria o componente relativo à inovação, ou progresso tecnológico não exógeno. Outro problema no uso deste modelo foi a suposição de uma mesma função de produção para todos os momentos em todos os países, dificultando seu uso para fins de comparação. Quando finalmente o progresso tecnológico foi inserido expressamente nos modelos de crescimento, passou a ser interpretado, ao menos nas primeiras versões, como um bem livre, acessível a todos, livre de encargos (FAGERBERG, 1994).

\footnotetext{
2 Documento que estabelecia metodologia específica para coleta de dados e produção de estatísticas sobre Pesquisa e Desenvolvimento, publicado pela OCDE em junho de 1963.

${ }^{3}$ Tais como fatores de produção continuamente substituíveis, rendimentos decrescentes e retornos constantes à escala. Soma-se a esse rol de hipóteses a concorrência perfeita e o equilíbrio de longo prazo.
} 
Nas décadas seguintes ao surgimento do modelo de Solow, incrementos tecnológicos ainda seriam creditados principalmente a elevações da relação capital/trabalho, até o ponto em que a produtividade viesse a crescer a taxas decrescentes ou até cessar, caso a relação estacionasse. Outros trabalhos, decorrentes do de Solow, apresentavam modelos que procuravam endogeneizar o progresso tecnológico, caracterizando-o como learning by doing, mas numa interpretação na qual tal progresso ainda era encarado como uma externalidade, um efeito colateral de outras variáveis, tais como o investimento. Essa premissa de neutralidade ${ }^{4}$ do progresso tecnológico funciona somente no plano teórico, para tornar possível alcançar e manter alguma relação de equilíbrio de longo prazo, como mencionado anteriormente. Sem essa premissa seria difícil definir qualquer tipo de equilíbrio, dado o caráter desequilibrador da inovação e do progresso tecnológico. Abordagens desse tipo, como outras que se seguiram, não levavam em conta o papel de ações e estratégias específicas de inovação, objetivando especificamente o progresso tecnológico, como os próprios esforços de P\&D (FAGERBERG, 1994).

Apesar de algumas tentativas nas duas décadas anteriores, em meados da década de 1980 este panorama começou a mudar. Reconheceu-se, a esta época, que tecnologia e conhecimento estão longe de serem bens públicos, tal como vinha sendo tratado pela teoria mainstream ${ }^{5}$, mas sim, investimentos feitos por empresas que buscam destaque e diferenciação, condenando os mercados a condições de concorrência imperfeita (ROMER, 1990).

A adição da dimensão do aprendizado adquirido por meio de produção, uso e inovação, na segunda metade dos anos 1980, enriqueceu o estudo do processo de inovação, com outras implicações dessa dimensão: a ênfase nos conhecimentos tácitos e específicos à situação de cada empresa frente à cadeia produtiva (o que reforça suas diferenças e especificidades); a consequente maior diversidade de atividades inovadoras, incluindo-se nesse contexto possíveis modificações organizacionais; o entendimento de que a inovação poderia surgir de setores pouco intensivos em P\&D (mas não ao ponto de questionar uma hierarquia setorial bem definida no âmbito da estruturação econômica); e a alusão constante a uma natureza sistêmica dos processos de inovação (ERBER, 2010).

Assim, a diferença essencial de análises sobre hiato tecnológico sem orientação neoclássica ${ }^{6}$ é como a tecnologia é conceituada: "teóricos ${ }^{7}$ de hiato tecnológico, [...] enxergam nas diferenças tecnológicas a causa primordial das diferenças entre as rendas per capita dos países” (FAGERBERG, 1994, p. 1155). De forma nenhuma a tecnologia é encarada como um bem público; ao contrário, essa vertente trabalha à exaustão como a tecnologia, conhecimento ou capacidades acumuladas são permeadas por organizações estruturais, sendo difícil e custosamente transferidas de firma para firma. As próprias firmas são caracterizadas por inúmeras combinações diferentes de estratégias e capacidades intrínsecas. Assim, a mudança tecnológica deve ser analisada como o fruto da inovação e de atividades de aprendizado interiores às organizações, além da interação entre elas. E esse processo é essencialmente cumulativo, endógeno e path-dependent. De maneira análoga podem ser tratados os países. Há, também, fatores específicos a cada um que influem, por diversos canais, diretamente no processo de mudança técnica, definindo assim o patamar tecnológico do país. Não raramente, estudiosos da área encaram cada país como um sistema tecnológico em separado, cada um com sua dinâmica específica. O termo "Sistema Nacional de Inovação” foi criado justamente com esse propósito (FAGERBERG, 1994).

Por exemplo, os late starters, ou países de industrialização tardia, enfrentam necessidades relativas a capital e outros fatores muito mais dramáticas do que os que se industrializaram anteriormente. Gerschenkron (1962) usa o exemplo da Alemanha, que se industrializou tardiamente, se comparada à Inglaterra. Os requerimentos de capital associados à escala eram bem maiores do que os que a vizinha enfrentou. Isso levou a Alemanha a ter de desenvolver uma série de instrumentos institucionais, pouco

\footnotetext{
${ }^{4}$ O progresso tecnológico não pode funcionar como um fator dinâmico do sistema, capaz de mudar sua trajetória e tendência. Nesse sentido, deve ser tratado como externalidade para que não tenha efeito sobre o sistema mas, sim, seja reduzido a um efeito desse sistema - garantindo, assim, o equilíbrio.

${ }^{5}$ Denotação para o Programa de Pesquisa Neoclássico, predominante na literatura econômica das últimas décadas.

${ }^{6}$ Higachi, Canuto e Porcile (1999) apresentam as principais linhas dos modelos que surgiram a partir dessa época que colocam o crescimento econômico de volta à agenda de pesquisa numa perspectiva substancialmente diferente da interpretação mainstream, os denominados Modelos Evolucionistas de Crescimento Endógeno.

${ }^{7}$ Podem ser citados, dentre outros, Martin Bell, Keith Pavitt, Bart Verspagen, Richard Nelson e Luc Soete.
} 
(ou nunca) observados em países de tradição industrial, visando à entrada nas indústrias mais dinâmicas e avançadas à época. ${ }^{8}$

Assim, o processo de catching-up, ou redução do hiato, não é de maneira alguma automático, mas requer um montante significativo de esforços e construção de instituições, ou "capacidades sociais”, como cunharam Ohkawa e Rosovsky (1973) para descrever os fatores que formavam a habilidade de uma nação de importar ou criar progresso tecnológico e organizacional. Mazzoleni e Nelson (2007) sugerem que casos de catch-up de sucesso envolvem basicamente três elementos, a saber: (i) fluxo de pessoas que saem de países atrasados para receber treinamento em países avançados ou consultores destes últimos que se deslocam para os países retardatários; (ii) participação ativa do governo, dando condições favoráveis e incentivos às indústrias nascentes e; (iii) flexibilização de direitos de propriedade intelectual. Ainda podem ser adicionados outros elementos a esses, conforme sugere Póvoa (2013): (iv) papel do governo na promoção de educação, treinamento e pesquisa aplicada; (v) inovações organizacionais ${ }^{9}$; (vi) investimento nas indústrias mais dinâmicas e progressivas existentes ${ }^{10}$ (PÓVOA, 2013).

Nelson e Wright (1992), analisando a trajetória dos Estados Unidos, notam que nada impede que a dinâmica que leva ao catch-up seja suficiente para ultrapassar os líderes, caso o sistema nacional de inovação de um país crie uma nova tecnologia ou obtenha completo sucesso em aderir a um nível técnico superior. No entanto, deixam clara sua descrença em que a experiência dos EUA possa ser replicada. Um dos motivos é a relativa perda de importância de uma nação para o progresso tecnológico. A importância crescente das empresas internacionalizadas, como explicita Fagerberg (1994), com atividades em diversos países, aceleraram os fluxos de comércio internacional de tecnologias, junto com a maior proximidade entre a ciência e a tecnologia, elevação das capacidades sociais com investimentos em educação e criação de arranjos cooperativos e institucionais com o intuito de apoiar a mudança tecnológica e estrutural, processos estes que aconteceram não apenas intra, mas também entre nações.

Logicamente, esta é uma análise para e entre países desenvolvidos, restando descobrir se ela se replica para os de industrialização tardia. Apesar da intensificação dos fluxos de comércio e da internacionalização de cadeias produtivas e tecnologias, os efeitos persistem sobre os países de origem das organizações. Ou seja, configura-se um processo interativo no qual as características das nações são carregadas pelas firmas, ao passo em que o que estas desenvolvem reflete diretamente sobre seus países (PATEL e PAVITT, 1991).

Estudos sobre hiato tecnológico mostram resultados bastante divergentes de acordo com os países selecionados e as variáveis explicativas. Soete (1981) aponta para o grande leque de estudos aplicados aos Estados Unidos e Alemanha, em comparação às "evidências escassas” e “menos convincentes” para outros países. No geral, estes estudos utilizam a renda per capita como proxy para o catch-up, e o consenso é de que modelos que testam hiato com apenas uma variável são insuficientes para explicar o processo de diferenciação no crescimento. A crítica comum é que fatores sociais, econômicos e institucionais não são levados em conta como deveriam e que o processo de catching-up é extremamente difícil, e resulta em sucesso apenas em países com características econômicas e institucionais muito adequadas. Tem sido cada vez mais aceito, até entre economistas neoclássicos, que análises que não incluem algum tipo de proxy relativa à inovação como atividade intencional das firmas ignoram uma das mais importantes fontes de progresso tecnológico nas economias capitalistas (FAGERBERG, 1994).

Estudos sobre competitividade internacional também sofrem críticas parecidas. Como notam Amendola et al. (1993), uma característica particular da inovação tecnológica é a sua natureza dinâmica intrínseca, como ressaltado neste trabalho, atributo que tem sido frequentemente negligenciado por estudos empíricos de competitividade em que relações estáticas são estimadas, tal como acontece em estudos de mensuração de hiato tecnológico.

\footnotetext{
${ }^{8}$ Wong (1999) segue essa linha de raciocínio em sua investigação sobre o rápido catch-up tecnológico de Coréia do Sul, Taiwan e Singapura.

${ }^{9}$ Corroborando a análise de Fagerberg e Godinho (2003, 2005).

${ }^{10}$ Conforme os apontamentos de Gerschenkron (1962), citado anteriormente. Tal como nota Póvoa, (2013), esta observação de Gerschenkron está "estreitamente ligada à de paradigmas tecnológicos, os quais determinam o avanço da fronteira tecnológica e o surgimento de 'janelas de oportunidade’. Os paradigmas tecnológicos, resultantes de inovações radicais, são determinados pelos países avançados e geram oportunidades tecnológicas devido à sua dinâmica singular” (p. 287).
} 
Tais análises estáticas, muitas vezes cercadas de hipóteses de equilíbrio, parecem pouco adequadas para compreender mudanças nos fluxos de comércio de cada país a partir de alterações nas respectivas atividades tecnológicas. Tanto a mudança tecnológica quanto os fluxos de comércio internacionais se encontram distantes do "fenômeno do equilíbrio". Para tanto, abordagens evolucionárias da mudança tecnológica e de trocas parecem estar teoricamente melhor amparadas para estudar e representar tais dinâmicas (DOSI et al., 1990).

Esta crescente linha da literatura que se inicia com os primeiros modelos de troca do tipo technology gap e product-cycle, tais como os de Posner (1961), Freeman (1963) e Vernon (1966), se desenvolve com as New Trade Theories, como a de Grossman e Helpman (1990) chegando às Evolutionary Theories, como a de Dosi et. al. (1990), que argumenta que as diferenças tecnológicas entre as nações são base fundamental para a dinâmica das trocas. A natureza do processo inovativo geralmente implica diversidade às taxas e à direção da inovação entre as firmas, setores ${ }^{11} \mathrm{e}$ países. Essa diversidade também significa que as firmas continuamente se expandem, encolhem ou fecham como resultado de seu sucesso tecnológico relativo (AMENDOLA et al., 1993).

Ainda, muitas atividades inovativas apresentam níveis diferentes de cumulatividade no processo de conhecimento técnico e são parcialmente apropriáveis pelos próprios inovadores. Isso contribui para as especificidades de cada país em cada setor no tocante à sua liderança ou hiato tecnológico. Estudos de cross-section sugerem, como visto em Fagerberg (1988), que a capacidade tecnológica relativa de um país em determinado setor é um forte determinante em sua participação nas exportações daquele setor no mercado mundial - e, pode-se acrescentar, a recíproca também parece ser verdadeira.

A maioria dos testes acerca da relação entre proxies de inovação e exportações dos países, interpretados a partir da abordagem de Hiato Tecnológico, faz uso de dados de cross-section de níveis de termos de troca (DOSI et al., 1990). Os resultados mostram correlações robustas entre as capacidades tecnológicas dos países e seu desempenho em exportações. No entanto, este tipo de teste não trata adequadamente a dinâmica pela qual as exportações são afetadas pela mudança tecnológica, acumulação de capital e alterações em preços de produtos e taxa de câmbio. Tais testes não permitem, também, a identificação de possíveis efeitos desta dinâmica que sejam específicos a cada um dos países (AMENDOLA et al., 1993).

A própria seleção das proxies é controversa, especialmente no tocante àquelas que deveriam representar inovação e progresso tecnológico. Patentes, comumente utilizadas para representar o potencial inovativo de um país, capturam-no apenas parcialmente, uma vez que subestimam a contribuição inovativa de setores nos quais elas não são um mecanismo importante de apropriabilidade. A introdução de um direito de monopólio formal sobre o uso do conhecimento tem implicações importantes sobre o volume e a direção das trocas, principalmente se comparados aos estudos clássicos, defensores do bemestar por meio das trocas livres, não protegidas. No entanto, é notória a sensibilidade do uso de dados relativos a patentes quanto às diferentes legislações dos países. A patente pode ter sido registrada em determinado país e, por motivos diversos, não pertencer a qualquer empresa de capital doméstico. Grandes mercados de tecnologia, com legislações favoráveis à propriedade intelectual acabam por atrair todo tipo de invenção detentora de certa "qualidade”, em termos de densidade tecnológica (SOETE, 1981).

Para seu teste, Soete (1981) estimou algumas regressões lineares simples do tipo $\log \log ^{12}$ utilizando variações nos fluxos de comércio entre indústrias explicadas em função de gastos com P\&D e número de patentes (como proxies para variáveis relativas à inovatividade), população e PIB (como proxies para “estágio de desenvolvimento”), intensidade em capital (proxy para “proporção de fatores”), e uma variável "resistência”, a distância entre os países. Seu modelo cross-section, específico por produto, utiliza "patentes" como a representação do "tempo de monopólio" de uma nova tecnologia e proxy para seu volume de produção. Há ainda uma tentativa de introduzir a variável tempo, ou um time-lag entre o

\footnotetext{
${ }^{11}$ É em nível setorial que as características da firma entram em interação específica com configurações macroeconômicas e institucionais: as definições sobre regimes tecnológicos, o padrão de competição vigente nos mercados, as características estruturais e institucionais de importação e exportação, bem como as relações no interior da cadeia produtiva, que estabelecem comportamentos voltados para diminuir a incerteza inerente a cada setor (ERBER, 2010).

12 Regressões do tipo log-log apresentam em seus coeficientes (betas) valores próximos ao que seriam as elasticidades.
} 
processo de $P \& D$ e a patente em si, por meio do uso de uma variável (gastos em $P \& D$ ) defasada em relação aos demais dados. Foram rodadas dois grandes grupos de regressões, uma relacionando P\&D e número de patentes em termos absolutos e a outra utilizando gastos em P\&D e patentes per capita. Ao contrário da maioria dos estudos até então, como nota o próprio autor, que fazem análise das trocas entre setores, ele busca analisar as trocas entre países, seguindo Leamer (1974).

Seus resultados indicam que o saldo do comércio internacional dos vários países da OCDE é uma função de seu desempenho tecnológico, apesar de assumir que as patentes representam uma proxy altamente "imperfeita” para inovatividade e desempenho tecnológico de um país, já que leva em conta apenas fatores endógenos, excluindo qualquer importação de tecnologia, crucial para muitos países da OCDE. Sugere o uso de uma variável que represente pagamentos e receitas tecnológicas, como medida de transferência e difusão internacional de tecnologia. ${ }^{13}$ Ao fim de seu trabalho, Soete reconhece o caráter estático da técnica, apontando que análises dinâmicas das mudanças na competitividade internacional, desempenho tecnológico e difusão internacional de tecnologia seriam muito mais satisfatórias, destacando a grande necessidade de pesquisa empírica para esta área de estudo, em que a evidência empírica e a interpretação dos fatos devem ser priorizados ante a modelagem teórica. ${ }^{14}$

Alinhada à conclusão de Soete, a literatura acerca da abordagem do crescimento via hiatotecnológico aponta que a capacidade doméstica de absorver conhecimento de outros países é um fatorchave para explicar as diferenças nas taxas de crescimento no tempo e no espaço, mas que não é um processo fácil, muito menos automático. Argumenta-se que a adoção exitosa de uma nova tecnologia é uma atividade custosa, que requer investimentos em ciência, pesquisa e desenvolvimento, bens de capital, infraestrutura adequada, etc. Como comumente exposto nessa literatura, um país raramente se beneficia de uma postura avessa à realização maciça de tais investimentos, e a probabilidade de falling-behind para os que não investem é maior do que a de catching-up (Verspagen, 1991, apud Castellacci, 2001).

Análises de catching-up e concorrência internacional apresentam problemas sérios de estimação: a dinâmica das variáveis é incompatível com a imposição de um estado estacionário, já que uma dinâmica de desequilíbrio constantemente prevalece. Neste contexto, não há uma configuração de equilíbrio de longo prazo nos mercados internacionais, uma vez que as participações dos países dependem de um processo contínuo de inovação, catching-up e falling-behind. Como consequência, tratamentos formais deste fenômeno devem adotar métodos próprios ou métodos ajustados à análise de séries não estacionárias (AMENDOLA et al. 1993).

Amendola, Dosi e Papagni (1993) enfatizam que a abordagem evolucionária da mudança técnica parece estar melhor amparada para representar as dinâmicas da evolução tecnológica e dos fluxos de comércio. No entanto, afirmam que devido ao menor número de restrições impostas aos modelos deste tipo, é mais difícil estabelecer ligações entre os resultados teóricos e a análise empírica. Em seu estudo, incluem a variável "inovação tecnológica" dividida em duas - atividades de inovação nas firmas com intenção de lucro através de conhecimento técnico, e conhecimento gerado através da produção normal, numa tentativa de ilustrar o learning by doing.

Os resultados indicam impacto de longo prazo da mudança técnica, em termos de patentes e investimentos em capital fixo sobre a dinâmica de exportação. Mudanças em salários e taxas de câmbio/termos de troca só apresentam impactos de curto prazo sobre a competitividade, sendo “absorvidos” no longo prazo. Patentes se mostraram, novamente, uma má aproximação do processo inovativo, já que subestimam a contribuição de setores onde elas não são um mecanismo importante de apropriabilidade. O efeito da defasagem dos impactos da tecnologia se mostrou longo - não há efeito imediato, começando a mostrar efeitos apenas no terceiro ano (quatro anos para patentes), e ainda se

\footnotetext{
${ }^{13}$ Vale ressaltar a importância da acessibilidade da inovação e tecnologia externas como fator potencializador das capacidades domésticas. Nelson (1996, p.93) afirma que: “As aptidões de todos são melhoradas por meio das criações ou descobertas de alguns. Isto é fundamentalmente diferente da evolução biológica”. Conforme nota Pereira (2012, p. 06) “a principal diferença entre o avanço dos processos técnicos e biológicos é decorrente do fato de que a tecnologia avança a partir de um processo de "evolução social e cultural".

${ }^{14}$ Ver Dosi, Grazzi e Moschella (2014) para um estudo recente de competividade com base nos atributos das firmas, a partir do caso italiano.
} 
arrastando por um longo tempo. Custos de trabalho mostraram fortes efeitos de curto prazo, com sinais alternados, desaparecendo no longo prazo. Salários e câmbio se mostraram fenômenos de curto prazo.

Uma adição interessante é que são utilizadas dummies para tentar captar efeitos fixos, específicos de cada país. Estes efeitos, chamados por eles de "competitividade estrutural”, incluem formas de organização industrial, instituições e políticas, que influenciam a capacidade das firmas domésticas de se inserir em mercados internacionais e explorar suas habilidades tecnológicas. Diante da forte significância destas variáveis para o modelo, os autores lembram que seu significado prático só pode ser discutido por meio de uma análise apreciativa, caso a caso, que descreva peculiaridades capazes de influenciar especificamente a parcela ocupada por aquela determinada nação no comércio internacional. O modelo não capta estruturas interativas, de feedback, que representariam ciclos “virtuosos' ou "viciosos”. Ainda, uma variável de efeito fixo (que se mostrou significativa estatisticamente) foi adicionada para tentar dar algum grau de heterogeneidade à amostra, especialmente em relação a variáveis institucionais. Em suma, apesar de ser um modelo consistente com a teoria evolucionária, a especificação falha na captação de efeitos interativos, choques ao longo do tempo e na formulação de uma proxy para o processo de inovação.

Castelacci (2001) propõe uma formalização de duas teorias distintas de mudança técnica, a ideia Kaldoriana de causa cumulativa e a abordagem do crescimento econômico via hiato tecnológico, aplicadas à Espanha. Encontra que uma taxa mais elevada de difusão ou criação de inovações em um país determina uma taxa de crescimento maior e mais estável da produtividade, mas apenas se sustentada por características tecnológicas das firmas, como o tipo de investimento que realizam e a distribuição dos ganhos de produtividade entre os obtentores de lucro e aqueles que buscam maiores salários. Em suma, encontra que o que "importa para o crescimento não é apenas inovação, acumulação ou distribuição, mas sua compatibilidade ao longo do tempo. Muitos regimes são possíveis, mas poucos levam ao crescimento induzido pela redução do hiato tecnológico. ” (Castelacci, 2001, p. 35).

Ainda conforme indica Castelacci, o processo de catching-up, pelo que se observa da literatura, está vinculado a três conjuntos de fatores: (a) atividades inovativas internas aos países ou regiões; (b) potencial para explorar tecnologias desenvolvidas em outros lugares (difusão); (c) fatores complementares, estruturais, que afetam o modo em que o potencial é aplicado na prática (2001, p. 8).

Em geral, encontra-se um predomínio de técnicas econométricas nas análises de hiato tecnológico (ou hiato de renda como proxy para o tecnológico) e verificação do impacto da inovação e variáveis afins sobre o desempenho dos países. Outro problema consiste, assim como nos testes específicos para hiato tecnológico, na agregação dos dados ${ }^{15}$. A heterogeneidade dos agentes econômicos, assim como a crescente e intensa internacionalização de empresas, são incompatíveis com modelos e equações gerais, representantes de países como um todo. Dados agregados ainda camuflam características exclusivas de setores com diferentes configurações tecnológicas (densidade tecnológica, taxa de inovação, apropriabilidade e difusão de inovações), distribuídos de maneira desigual entre os países, sugerindo que uma micro-fundamentação deve ser considerada em modelos de catching-up.

Uma análise não estática e não agregada deve ser considerada, ainda, em função dos muitos mecanismos cumulativos que incrementam a competitividade das firmas em mercados internacionais, processo pelo qual o "sucesso tende a gerar sucesso". Firmas têm competências acumuladas por meio de processos próprios de busca pela inovação. Estas competências das firmas são continuamente atualizadas e incrementadas, assim como suas atividades de produção, marketing, investimento, P\&D, dentre outras. Essa dinâmica acaba implicando retornos crescentes, resultado este compatível com a abordagem neoclássica somente a partir do surgimento dos modelos de crescimento endógeno ${ }^{16}$.

\footnotetext{
15 Entram para o rol de análises agregadas estudos como o Lederman e Maloney (2003), que liga padrões de P\&D a incrementos no PIB per capita de países com altas taxas de desenvolvimento tecnológico da Ásia e Europa versus o norteamericano, evidenciando o forte investimento de latecommers como a Coréia do Sul; Amsgen, Tschag e Goto (2001) o fazem numa análise específica do P\&D da economia de Singapura.

${ }^{16}$ Modelos de Crescimento Endógeno se distinguem, também, pela presença de retornos não-descrescentes do capital, seja na forma de externalidades do conhecimento (aprendizagem) ou acumulação de capital humano. Destacam-se nesta linha os trabalhos de Romer (1986, 1990), Lucas (1988) e Aguion \& Howitt (1990). Apesar de avanços, estes modelos ainda assumem
} 


\section{Inovação e Hiato Tecnológico na Literatura Brasileira}

Entre os anos de 1990 a 1994, até por conta da abertura comercial, havia grande preocupação quanto à competitividade internacional da indústria brasileira. Enquanto as empresas brasileiras foram expostas à acirrada concorrência internacional, sua internacionalização elevou significativamente o acesso a novos mercados e novas fontes de informação e aquisição de tecnologias e outros conhecimentos. Com isso, o conhecimento e a inovação passaram a ser vistos como forças imprescindíveis à sobrevivência e à aquisição de vantagens competitivas na economia brasileira (ERBER, 2010; SILVA, 2006).

Entre os trabalhos sobre o tema, ganha destaque por amplitude e profundidade o Estudo da Competitividade da Indústria Brasileira (ECIB), realizado em 1992, que foi uma coordenação de ações de um consórcio de instituições organizado pelo Ministério da Ciência e Tecnologia. Esse estudo foi feito com 661 empresas, com representações setoriais, além de distintos tamanhos e valores de produção, mediante um questionário pautado em atividades inovativas (ERBER, 2010).

Estudos desse tipo eram dificultados pela relativa escassez de dados, situação que persistiu até à realização da primeira PINTEC (Pesquisa de Inovação Tecnológica, do IBGE), em 2000, que começou a prover dados específicos sobre inovação, $P \& D$ e estratégia competitiva das empresas de maneira mais completa do que a PAEP e a PAER (Pesquisas de Atividade Paulista e Regional, respectivamente), lançadas anteriormente também com base no Manual de Oslo, editado pela primeira vez em 1992, reflexo do crescente interesse no estudo da inovação.

A literatura brasileira dos anos 1990, tal como Erber (1992), Coutinho e Ferraz (1994), Ferraz, Kupfer e Haguenauer (1996), utilizando a estrutura da taxonomia de Pavitt, propôs que os setores poderiam ser divididos em motores, que geram as principais inovações, baseadas em ciência, receptores, com demanda atendida principalmente pela oferta de outros setores e os intermediários, com sua demanda suprida em parte por esforços internos. Os setores intermediários, como, por exemplo, bens de capital e insumos de produção, atuariam como fornecedores de inovações entre si e para os receptores. A essa taxonomia setorial, Erber (1992) associava uma taxonomia de intervenções estatais que seguia a relação risco/custo da inovação (ERBER, 2010).

Por ser baseada no Manual de Oslo, a PINTEC permitiu o início da realização de estudos comparativos com os países OCDE. Viotti, Baessa e Koeller (2005) realizaram uma comparação do Brasil com a União Europeia para o período 1998-2000. Concluem, com base nos baixíssimos índices de inovação brasileiros (quando comparados à Europa), que "é pobre o dinamismo do processo de inovação da indústria brasileira (...) o aprendizado passivo parece ser dominante entre as empresas" (VIOTTI; BAESSA; KOELLER, 2005, P.684). Trabalho semelhante foi feito por Bagatolli (2008), com base na segunda PINTEC, de 2005, mas com resultados também equivalentes.

Kannebley et al. (2004), em uma extensão a Kannebley (2003), aproxima-se dos trabalhos de Macedo e Albuquerque (1999), Quadros et al. (2001), Adreassi e Sbragia (2002), Sbragia et al. (2002). Buscam identificar as características das empresas inovadoras a partir das informações da PINTEC de 2000, para a indústria e seus setores CNAE (Classificação Nacional de Atividades Econômicas), aplicando modelos de regressão logística (Logit) e probabilista (Probit) para um universo de 72 mil empresas, a fim de estilizar atributos das empresas "inovadoras" ou "não inovadoras". Encontra que as empresas "não inovadoras” são majoritariamente micro ou pequenas empresas, de capital nacional, não exportadoras e independentes de grupos empresariais; já as inovadoras têm caracterização mais complexa, já que há significância de todas as variáveis consideradas importantes. Os autores destacam que a importância está na combinação de fatores da firma com características industriais, mas com destaque para três combinações: exportadoras, com 100 ou mais empregados e de capital estrangeiro; exportadoras, 250 ou mais empregados e capital nacional; e exportadoras, com mais de 30 mas menos de 100 empregados e pertencentes a setores de média-baixa, média e alta oportunidades tecnológicas.

Atenta-se para o fato de a característica "exportadora” ser dominante entre as empresas inovativas. Percebe-se que há a discutida interação entre resultados e esforço de inovação de uma empresa - ela exporta por ser inovadora ou inova por estar no mercado internacional, obter mais ganhos e estar exposta

equilíbrio geral competitivo, racionalidade maximizadora e fatores continuamente substituíveis, todos estes empecilhos para o estudo da inovação e do progresso tecnológico. 
a uma concorrência mais qualificada? Apesar de não indicar uma causalidade, o trabalho indica que essa tendência da literatura se aplica ao caso brasileiro, confirmando para o país a importância do esforço de inovação para o desempenho competitivo das firmas. ${ }^{17}$

Com o objetivo de identificar padrões inovativos intersetoriais, Campos (2005) utiliza dos dados da PINTEC de 2000 para empregar análises de cluster $^{18}$ a fim de investigar a mudança tecnológica brasileira no período referido, agrupando setores com base em três traços principais - fontes de inovação, formas de conhecimento e aprendizagem e tipos de resultados inovativos, num paralelo com a Taxonomia de Pavitt (1984). Este trabalho é ampliado em Campos e Ruiz (2008), também com base na PINTEC de 2000 mas onde são adicionados mais dois traços - foco da trajetória tecnológica e características de estrutura e desempenho. Este estudo também aponta a importância de se considerar a diversidade intersetorial para qualquer tentativa de compreensão do comportamento inovativo da indústria no Brasil, e seus resultados apontam que os padrões inovativos são fortemente influenciados pelas chamadas oportunidades tecnológicas ${ }^{19}$, colocando os setores com melhores indicadores de tecnologia entre os de maior dinamismo inovativo. A forte heterogeneidade, segundo os autores, impõe que "políticas industriais lineares de estímulo à inovação podem não alcançar resultados efetivos para toda a indústria brasileira (...) as idiossincrasias de cada setor devem ser pesadas quando se pretende adotar medidas que de fato fomentem a atividade inovadora na indústria” (Campos e Ruiz, 2008).

Também utilizando análise multivariada, Taveira e Gonçalves (2012) agrupam setores industriais do Brasil com base em indicadores de esforço tecnológico construídos a partir dos dados da PINTEC de 2011. A análise de componentes principais e de clusters desenvolvida pelos autores indica que os setores industriais brasileiros podem ser caracterizados em torno de quatro características: (a) esforço inovativo, que representa setores com maiores gastos em atividades inovativas se comparadas ao resto da indústria, onde se enquadram; (b) esforço próprio, com setores que priorizam a produção interna de tecnologia via P\&D em vez de comprá-la; e (c) esforço de desenvolvimento e implementação de inovação, abrangendo setores que desenvolvem conhecimento tecnológico internamente, separando-os dos que já possuem conhecimento e dispendem recursos para desenvolver implementar inovação e; (d) esforço de implementação, com setores majoritariamente engajados na implementação das inovações.

Refino de Petróleo e Fabricação de Veículos se destacam nos dois primeiros, Fabricação de Aparelhos Eletromédicos foi identificado como grande gerador de conhecimento, enquanto Fabricação de produtos alimentícios por apresentar alta importação de conhecimento. Em paralelo à taxonomia Pavittiana, os autores colocam 44\% da amostra de setores como dententores de "alto investimento em inovação" e os 56\% restantes como "dominados por fornecedores”, com baixa conhecimento tecnológico mas, apesar dessa divisão, ressaltam a heterogeneidade dos setores produtivos no Brasil tal como outros autores que buscaram classificar os setores industriais brasileiros "internamente" e com base em dados de apenas um período ${ }^{20}$, sem comparação com outros países ou no tempo.

Intentando observar padrões comportamentais, Avellar et al. (2012), com base nos dados da PINTEC de 2005, investigam as relações entre capacitação inovativa, investimento e produtividade das firmas brasileiras divididas em diversos subsistemas, segundo o caráter da atividade produtiva em questão. Para o modelo econométrico de Cross-Section são utilizados microdados ${ }^{21}$ do período e variáveis explanatórias dividas em três grupos: (i) Características da firma; (ii) Capacitação tecnológica e

\footnotetext{
${ }^{17}$ Ver De Negri (2004) para uma análise probabilística do desempenho exportador brasileiro segundo capacidades tecnológicas das firmas domésticas.

${ }^{18}$ Técnica de análise multivariada que permite resumir grandes conjuntos de informações em um número menor de parâmetros (Manly, 1986 apud Campos, 2005).

${ }^{19}$ Fases no processo de difusão internacional de paradigmas tecnoeconômico que favorecem a entrada de latecomers, mais especificamente as de introdução de novas tecnologias, esta inicial, com menores barreiras de investimentos e experiência; e de maturidade, quando a tecnologia já está difundida e portanto mais acessível (Possas, 2003).

20 Para mais trabalhos que analisam períodos específicos da PINTEC, ver Maculan et al (2009), para uma análise de indicadores para o Amazonas a partir da PINTEC 2005; Kobs et al (2008), usam a PINTEC 2005 para analisar indicadores de inovação para o Paraná; Leite (2011) estuda fatores com maior probabilidade de induzir inovação, com base na PINTEC 2008; Tironi e Koeller (2006) numa análise do financiamento público à inovação com base na PINTEC 2000.

${ }^{21}$ Dados com o maior nível de desagregação possível, relativos a firmas específicas, individualmente. Estes dados não estão disponíveis publicamente e requerem permissão especial do IBGE para sua utilização, por motivos de confidencialidade.
} 
(iii) Investimento. Ressaltam, tal como Campos (2005) e Campos e Ruiz (2008), as dificuldades em encontrar padrões de comportamentos dada a heterogeneidade das indústrias individualmente, sustentando que trabalhar com Sistemas Produtivos pode render mais resultados por agregar indústrias com características mais homogêneas e facilitar a identificação de padrões internos e o estabelecimento de diferenças entre os subgrupos.

Seus resultados indicam que há relação positiva entre o grupo (i), composto por Tamanho, Origem de Capital e Pertencimento a Grupo, e o desempenho produtivo ${ }^{22}$ - tal resultado é encontrado também para as variáveis do grupo (ii), composto por indicadores P\&D e de Cerificações, estes com significância mais acentuada, para a produtividade do que os primeiros. Tais relações corroboram as evidências empíricas de que firmas inovadoras apresentam produtividade superior às não inovadoras, apesar da dificuldade em estabelecer padrões de comportamento mesmo após a separação das indústrias em Sistemas Produtivos.

Furtado e Carvalho (2005), a partir dos dados da PINTEC de 2000, realizaram um estudo comparativo com Estados Unidos, Japão, Coreia, Alemanha, Espanha, França, Itália, Reino Unido e Noruega, concluindo que o Brasil é detentor de baixa intensidade tecnológica (representada por gastos em P\&D como proporção do valor adicionado) em relação aos países estudados, situação que se agrava em setores de média e alta intensidade tecnológica, sendo que a diferença de intensidade entre os setores menos intensivos e mais intensivos em tecnologia é a menor dentre todos os países estudados, refletindo a deficiência brasileira em setores de alta tecnologia e maior valor agregado.

Estudos com foco em patentes, como o de Urraca (2008), corroboram este diagnóstico - dos 18 países selecionados, o Brasil detém apenas 0,13\% das patentes. Setorialmente, Urraca nota afastamento do Brasil em relação aos níveis de inovação dos países líderes e asiáticos, que têm suas patentes concentradas em setores de alta intensidade tecnológica (como o de eletrônica, do qual o Brasil está praticamente ausente em termos de patentes), e aproximação dos países sul-americanos, que concentram suas inovações em setores intensivos em recursos naturais e trabalho (ERBER, 2010). Este cenário reforça a necessidade de um mapeamento não apenas quantitativo mas qualitativo dos esforços inovativos. Outros trabalhos mostram que o Brasil se destaca na América Latina, mas está ainda muito distante do resto do mundo. Neste rol encontram-se Cruz e Mello (2006), Rodriguez, Dahlman e Salmi (2008), Erber (2000), De Negri e Turchi (2007).

Oreiro, Basilio e Souza (2013) vão no sentido contrário a Amendola et al (1993) e enfatizam o câmbio como fator determinante e essencial para o catching-up tecnológico e desenvolvimento econômico. Partem do conceito de taxa de crescimento de equilíbrio do balanço de pagamentos, desenvolvido por Thirlwall $(1997,1999,2002)$, considerado essencial para um modelo de crescimento liderado por exportações. No entanto, tal modelo seria prejudicado a depender das elasticidades-renda de importações e exportações, sendo assim necessária uma taxa de crescimento compatível com equilíbrio no balanço de pagamentos. Os autores consideram catching-up apenas de renda, e lembram que para que ele ocorra nestas condições as empresas da economia doméstica deverão já estar operando em níveis próximos à fronteira tecnológica mundial em uma estrutura produtiva consideravelmente diversificada (OREIRO et al, 2013, p. 3).

Diferentemente da modelagem modelística de Oreiro et. al. (2013), uma abordagem histórica sobre o catching-up é feita por Arend e Fonseca (2012), onde os autores seguem a proposta de modelo histórico-analítico de Perez (2004), sobre ondas longas de desenvolvimento ${ }^{23}$. Afirmam que países retardatários só colocarão em movimento um processo autônomo de superação do atraso por meio de suas empresas locais, proporcionando uma trajetória de desenvolvimento menos vulnerável às idas e vindas do capital internacional. Países periféricos se beneficiam dos spillovers ${ }^{24}$ de indústrias que se veem em

\footnotetext{
${ }^{22}$ Medido pela produtividade do trabalho.

23 Sugere que na primeira metade de uma onda longa de desenvolvimento (denominada Instalação e dividida em fases Irrupção e Frenesi), as ideias econômicas historicamente pendem para o liberalismo, tornando o período caracterizado pela dominância financeira, quando a revolução tecnológica tende a gerar uma bolha seguida de colapso financeiro. Após o colapso, segue-se um momento de rearranjo institucional (este chamado de Desprendimento e dividido em Sinergia e Maturidade), que define o estilo de crescimento da segunda metade da onda e caracterizado pelo domínio do capital produtivo e predominância do ideário intervencionista do Estado (Arend e Fonseca, 2012, p. 35-37).

${ }^{24}$ Como a literatura comumente se refere a "transbordos tecnológicos".
} 
mercados saturados nos países centrais, reduzidos em termos de taxas de lucro e ganhos de produtividade. Confirmando-se esse processo, as economias periféricas podem ingressar em uma trajetória de atraso tecnológico por estarem presas a um mecanismo de catching up dependente das economias centrais, já que a cada novo paradigma tecnológico que se instala, necessitarão de novos investimentos para seu upgrade tecnológico, mas a probabilidade de eles ocorrerem na fase inicial do ciclo é muito baixa (AREND E FONSECA, 2012).

Sua análise para o caso brasileiro pontua que o país conseguiu um catch-up relativo até a década de 80, com início no Plano de Metas do governo de Juscelino Kubitschek, que decretou a entrada maciça de investimentos de multinacionais como veículos de difusão de tecnologia e dinamização da economia, mostrando-se vulnerável por não garantir “endogenia técnica”"25. Após esse período, de maturação de tecnologias da Quarta Revolução, saturação de mercados e perdas de produtividade nas economias centrais, deu-se a irrupção do novo paradigma tecnoeconômico, evidenciando a vulnerabilidade dos países presos ao crescimento via poupança externa, dentre eles o Brasil. Os investimentos externos na economia brasileira não internalizaram as "máquinas do crescimento Schumpeteriano da Quinta Revolução Tecnológica” (Arend e Fonseca, 2012, p. 53).

Portanto, para a quebra desse círculo vicioso, de vinculação doméstica a padrões tecnológicos de obsolescência crescente no exterior, é preciso que as empresas domésticas entrem em um processo de produção gradual de inovações, gerando mudanças técnicas não apenas incrementais, mas que visem às revolucionárias, até que possam romper definitivamente com a dependência das empresas multinacionais, que geralmente internacionalizam para países periféricos o desenvolvimento de produtos e processos pouco inovadores, conforme nota Amsden (2001, apud Arend e Fonseca, 2012).

Galeano e Feijó (2010) analisam diferenças de crescimento das regiões brasileiras em relação aos Estados Unidos, com base em um modelo formado por variáveis de produtividade, inovação e hiato tecnológico, seguindo a modelagem de León-Ledesma (2002), no qual a produtividade do trabalho estimulada pela demanda é chave para o processo de desenvolvimento, a partir da Lei de KaldorVerdoorn $^{26}$ e do efeito induzido da aprendizagem e competitividade "não-preço" tem sobre o crescimento. Encontram, a partir do sinal da variável gap, que o crescimento desigual influenciou a persistência dos desempenhos diferentes em produtividade e dinâmica de investimentos, gerando um ciclo que favorece a persistência do crescimento desnivelado, mesmo quando há ganhos de produtividade, estes incorporados majoriatamente por regiões mais ricas e desenvolvidas, dificultando o nivelamento do desenvolvimento.

A fim de estudar o hiato tecnológico entre as economias brasileira e norte-americana, Frölich e Nakabashi (2010) se baseiam nos modelos de crescimento de Solow (1956) e de difusão tecnológica de Nelson e Phelps $(1966)^{27}$ para explicar variações no produto per capita dos dois países, funcionando como proxy de longo prazo para o progresso tecnológico. Seus resultados indicam que o progresso tecnológico da economia norte-americana foi de 78,3\% no período analisado (1982-2003), enquanto o progresso tecnológico da economia brasileira foi de 21,9\% no mesmo período. Em comparação, o PIB norte-americano se elevou em quase $60 \%$ enquanto o brasileiro apenas $15 \%$ no período. Os autores notam que o baixo nível educacional do Brasil dificulta a capacidade do país de absorver tecnologia da fronteira, uma vez que um nível menor de capacitação técnica e científica implica inaptidão relativa em avaliar e adotar novos métodos de produção. Para eles, o aumento do hiato entre "técnicas disponíveis e efetivamente empregadas” pelos brasileiros, potencializada pela inaptidão técnica, prejudicou o desempenho da economia brasileira no período estudado.

\footnotetext{
${ }^{25}$ Conforme definem Arend e Fonseca (2012, p. 52).

${ }^{26}$ Estabelece uma relação causal entre a taxa de crescimento da produtividade do trabalho e a taxa de crescimento da produção, onde o crescimento da produção determina o crescimento da produtividade. Nele, o crescimento da produtividade é induzido e o crescimento das exportações, ao estimular a produção, pode estabelecer um círculo virtuoso de crescimento (Galeano e Feijó, 2010, p. 07).

${ }^{27}$ Unem a noção de Solow $(1956,1957)$ de que no longo prazo o nível da renda per capita da população depende somente da taxa à qual aumento o progresso tecnológico (cuja proxy é a “efetividade do trabalho”) à implicação do modelo de Nelson e Phelps (1966) de que a taxa à qual o progresso tecnológico se dá é proporcional ao grau educacional atingido pela população e ao hiato entre progresso tecnológico “teórico” e “prático” (Frölich e Nakabashi, 2010).
} 
Em trabalho recente aplicado ao caso brasileiro, e provavelmente o de escopo mais próximo ao do presente estudo, Melo, Fucidji e Possas (2015) discutem, a partir da abordagem evolucionária, aspectos de política industrial e a relação entre hiato tecnológico e competitividade das firmas. Destacam a imperatividade do conhecimento das especificidades da estrutura industrial nacional para o desenvolvimento de políticas que possibilitem às firmas reduzir a defasagem tecnológica das líderes setoriais, conferindo assim consequentes ganhos de competitividade. Essas políticas devem, necessariamente, passar pela indução da realização de atividades inovativas internamente às firmas fonte do desenvolvimento de competências produtivas e tecnológicas na atividade industrial.

Representam o hiato tecnológico por meio de indicadores que traduzem o esforço inovativo das firmas em relação a países como Bélgica, Alemanha, França e Dinamarca, encontrando maior hiato em setores de Alta e Média-Alta tecnologias, com alta discrepância principalmente em indicadores relativos a Gasto em P\&D. Presumem, ao não constatar melhora nos indicadores setoriais, que as políticas industriais da história recente brasileira aparentemente não surtiram efeito sobre o esforço inovativo das firmas e, consequentemente, sobre a posição tecnológica e competitiva do Brasil frente aos seus concorrentes no mercado internacional.

De maneira geral, nota-se na literatura brasileira sobre inovação e catching-up um consenso quanto ao baixo nível de produção de conhecimento e o baixo dinamismo inovativo da indústria brasileira imbricado aos baixos níveis educacionais e às instituições de apoio ao desenvolvimento tecnológico, num conjunto de capacidades sociais pouco desenvolvidas. Ainda que o trabalho da análise da inovação no Brasil tenha sido facilitado após o advento do Manual de Oslo e da PINTEC, em diversos trabalhos sobre anos determinados da Pesquisa de Inovação Tecnológica, ainda não houve um esforço de análise de todo o período de dados disponível em comparação com dados equivalentes para outros países.

Considerando-se a inovação um dos motores do progresso tecnológico e este um dos principais determinantes do desenvolvimento econômico, o cenário brasileiro é preocupante. Predominam análises sobre anos determinados das pesquisas industriais diversas (PIA, PINTEC, PAEP, PAER) havendo, ainda, relativa escassez de trabalhos nacionais que busquem mensurar o quão atrás estamos dos países líderes em produção científica e tecnológica e qual é nossa posição atual no cenário tecnológico mundial, bem como a evolução desse - presumido - atraso no tempo, preocupação essa constante e comumente presente na literatura econômica internacional.

Dentre os existentes, tanto nacionais quanto internacionais, boa parte acaba por utilizar dados macroeconômicos para analisar um fenômeno essencialmente microeconômico - a criação de conhecimento, processos de $\mathrm{P} \& \mathrm{D}$ e inovações que levam a avanços tecnológicos. O uso de proxies das variáveis de interesse (capacitação técnica, esforços de inovação, hiato tecnológico, entre outras) formuladas a partir de dados agregados ou indicadores de inovação muito amplos, tais como as patentes, têm se mostrado inconsistentes para explicar o hiato tecnológico entre os países e diferenças em seus potenciais inovativos, principalmente se realizadas as análises em determinados pontos do tempo, isoladamente.

\section{Considerações Finais}

A descrição da mudança econômica baseada em mecanismos de seleção "natural”, rotinas e processos de busca e seleção de técnicas por parte das firmas ${ }^{28}$ é nada se não a caracterização um movimento de longo prazo, movido pelo aprendizado das firmas e sua influência sobre elas mesmas e os outros stakeholders do mercado e da economia como um todo, concomitantemente à influência que estes últimos têm sobre elas e seus processos de tomada de decisão. Natural sob esta ótica, então, entender a mudança econômica como um processo moroso, com resultados pouco observáveis em um instante determinado no tempo, mas evidentes quando analisados sob uma perspectiva histórica, uma análise $a o$ longo do tempo e não do momento no tempo. Ou seja, o modo correto de análise da mudança econômica, nesta perspectiva, é dinâmico, passando necessariamente pela identificação de padrões ao longo do tempo e pela perspectiva histórica do objeto de análise - neste caso, as indústrias como agregados imediatos de firmas individuais ou, mais agregadamente se desejado, países.

\footnotetext{
${ }^{28}$ Tal como na tradição Schumpeteriana.
} 
Entretanto, seria ingênuo defender que a mudança não ocorre, por vezes, de maneira muito rápida. É, portanto, imperativa a identificação do mecanismo que pode fazer um processo tão lento se acelerar. Em sua clássica obra Capitalismo, Socialismo e Democracia, Joseph Schumpeter introduz o fenômeno da concorrência para contextualizar e justificar o surgimento das inovações, com uma diferença crucial: a de que concorrência é um processo, tal como descrito até aqui, e não um mecanismo que leva a um fim inevitável, um estado terminal de equilíbrio. A concorrência, por sua vez, não implica atomismo de mercado, um grande número de firmas ofertantes, mas sim, uma interação entre estas mesmas firmas capaz de gerar mudanças estruturais no sistema, tornando-o dinâmico. Sendo assim, tal processo é completamente compatível com o oligopólio, e até com o monopólio (tendo em conta a concorrência potencial), caminhos praticamente "naturais" de um sistema concorrencial que beneficia empresas que inovam e se destacam das demais, estas penalizadas com perda de sua participação no mercado e, no limite, sua extinção (SCHUMPETER, 1943).

A concorrência como processo, por sua vez, tem uma dimensão plenamente ativa de diferenciação. Capitalistas recorrem, deliberadamente, a formas de financiamento para viabilizar investimentos em inovação de naturezas diversas: produtos, processos, arranjos organizacionais, uso de novas matérias primas, entrada em novos mercados ou toda e qualquer mudança que dê oportunidade ao investimento lucrativo. Concorrência nada tem a ver com o número de players de um mercado mas, sim, com a sua capacidade de gerar mudanças ao longo do tempo, inovações que geram efeitos dinâmicos. O que move o sistema, em suma, é a inovação, radical ou incremental, promovida pelo empresário Schumpeteriano, que assume a figura do líder, do inovador, do agente ativo e propenso ao risco, impelido pela busca contínua pelo lucro. A presença de agentes que visam a lucros torna "essencialmente endógeno o aparecimento de inovações, que constituem o mecanismo de alterar as condições do ambiente econômico, tornando cruciais as decisões capitalistas de investir, no sentido de modificar irreversivelmente o contexto em que são tomadas” (POSSAS, 1991, p. 82).

Sendo a atividade econômica voltada para o lucro, este se torna condenado à diluição na ausência de inovações, responsáveis pela abertura de novas possibilidades de criação de espaços econômicos passíveis de apropriação, ou seja, a criação de vantagens que podem ser convertidas em lucros monopolistas, temporários em maior ou menor grau. A concorrência, portanto, é processo de interação das unidades econômicas que buscam lucro mediante esforço inovativo, ou esforço de diferenciação de suas concorrentes (POSSAS, 1996). Com a introdução de inovações ao sistema concorrencial, a concorrência passa a não se restringir somente à sua óbvia e tradicional dimensão passiva, de eliminação gradual de diferenças, através de imitação, redução de lucros ou expansão da oferta - a busca Ricardiana do lucro onde ele existe. Mas, sim, impera sua dimensão ativa, da busca pelo lucro onde ele ainda não existe. Esta busca pelo "lucro inexistente" ocorre por meio de inovações, o que por sua vez tem consequências em dois níveis distintos: o nível micro, de alteração contínua das estruturas produtivas, e o nível macro, onde as major innovations afetam a economia de maneira global, afastando-a de sua posição inicial.

Apesar de ignorado ou simplificado além da conta durante muito tempo, o avanço tecnológico é (mais fortemente desde os anos 1980) reconhecido por economistas de diversas vertentes teóricas como sendo uma força-chave por trás do mais amplo leque de fenômenos econômicos: variações da produtividade, competição entre firmas em indústrias com níveis variados de densidade tecnológica, padrões de comércio internacional de bens manufaturados, diferenças no PIB per capita e taxa de crescimento, dentre outros. E, apesar de ter sua importância reconhecida, questões como a inovação e a mudança tecnológica têm seu papel reduzido em modelos de análise econômica a fim de não ameaçarem qualquer estrutura teórica do arcabouço ortodoxo, o que não significa que não tenha havido mudanças significantes. Possas (2002) elenca contribuições importantes de uma "Nova Economia do Desenvolvimento", primordialmente (i) a recolocação do tema teórico do desenvolvimento; (ii) a busca por microfundamentos e (iii) a preocupação com fatores endógenos, com destaque para o progresso técnico e a presença de retornos crescentes (Possas, 2002 apud Dweck, 2012, p.57).

O pré-requisito de que seu modelo de análise deve estar alinhado com conceitos como maximização e equilíbrio força os teóricos ortodoxos a simplificar e estilizar mais do que o necessário os padrões de Pesquisa e Desenvolvimento (P\&D), estrutura e características industriais, dentre outros 
aspectos, tornando secundário características essenciais da competição Schumpeteriana, como a diversidade de características das firmas e das próprias indústrias.

Ao tratar o avanço tecnológico deve-se levar em conta um processo em que, a todo momento, numerosos esforços diferentes e simultâneos estão sendo realizados a fim de promover avanços à tecnologia, esforços estes concorrentes uns dos outros e cujos vencedores só serão conhecidos em um momento futuro. Assim, temos empresas diferentes, com trajetórias de aprendizado diferentes, mecanismos de busca e seleção diferentes, e portanto estratégias distintas; isso significa que teremos também esforços de diferenciação diferentes mesmo sob os mesmos sinais econômicos e mercadológicos, como já discutido. Nesse sentido, sendo a inovação o principal mecanismo de diferenciação e de ganhos de vantagens comparativas, teremos firmas realizando esforços inovativos distintos, definidos por sua capacidade financeira (advinda também dos lucros que os esforços anteriores proporcionaram) e por sua interpretação dos sinais emitidos pelo ambiente concorrencial e pelas demais instituições componentes do sistema econômico, segundo seu conhecimento acumulado ao longo do tempo.

Sendo neste nível microeconômico onde de fato acontecem a criação de conhecimento e as inovações, deve ser a partir dele que o problema da mudança tecnológica deve ser analisado. Podemos, assim, encarar uma indústria como resultado das características de suas firmas e, mais agregadamente, características de um país como um agregado das características de suas firmas e as indústrias que elas compõem. Finalmente, havendo diferenças tecnológicas entre firmas, a agregação no sentido exposto dará, também, diferenças tecnológicas entre indústrias e países - um hiato entre a capacidade tecnológica de duas indústrias ou duas nações em dado momento do tempo.

As causas da existência e manutenção do hiato tecnológico entre dois países são, como se poderia imaginar, muitas. No entanto, se queremos avaliar dois países quanto à sua capacidade tecnológica podemos nos ater a como suas firmas se esforçam para inovar e quanta inovação elas produzem de fato. Esses dois fatores podem ser reflexos de como estas firmas de uma determinada nação interpretam os elementos econômico-institucionais, agem para se diferenciar, reagem à concorrência, além de serem reflexos da qualidade da mão de obra e da pesquisa de um país, dos incentivos públicos à criação de conhecimento e inovação, do sistema tributário, legislativo, da burocracia envolvida para empreender e inovar, dentre outros diversos fatores. Mais que isso, como e quanto os países inovam é indicativo sólido da sua capacidade de produção de tecnologias não apenas em termos absolutos, mas também em termos relativos. Ou seja, assumindo que tecnologicamente os países são reflexos de suas firmas, a capacidade de um país alcançar outro será expressa pelas capacidades relativas destes países de produzirem inovações por meio de suas firmas e instituições.

A maior parte da literatura que aborda a questão do hiato entre países o faz em termos mais "gerais”, no sentido de agregação econômica dos quesitos estudados. Constantemente, a noção de catchup faz alusão à redução de diferenças entre PIB per capita ou, no máximo, entre produtividade geral de um grupo de países. Como vimos, estudar diferenças inovativas e tecnológicas é, também, estudar a capacidade de crescimento e desenvolvimento dos países, já que as economias são aqui encaradas como movidas pela mudança tecnológica. A própria evidência história indica que os grandes processos de catching-up de renda e produtividade observados ao longo do tempo se deram principalmente a saltos inovativos e tecnológicos.

Conforme apontam Freeman e Soete (1997) e Freeman e Louçã (2001), durante a maior parte do século XIX o líder tecnológico do mundo capitalista era o Reino Unido, com um PIB per capita superior à média dos demais países em mais de 50\%, até que Estados Unidos e Alemanha começaram a reduzir o gap, não apenas imitando as tecnologias mais avançadas produzidas e utilizadas na economia líder, mas principalmente desenvolvendo novas formas de organização produtiva e distribuição, ou seja, inovando. No caso norte-americano, esse processo levou a um novo sistema, pautado em produção e distribuição em massa e exploração de economias de escala; na Alemanha, destacou-se a inovação em organização produtiva, principalmente em respeito à Pesquisa e Desenvolvimento e ao desenvolvimento dos setores de Químicos e Engenharia. Observamos, hoje, EUA e Alemanha apontados como líderes em produção de inovação e tecnologia, juntamente a Japão e Coreia do Sul, países que também passaram por revoluções tecnológicas nas últimas décadas - hoje, o Reino Unido já não é a grande referência em termos de produtividade e desenvolvimento tecnológico. É bastante razoável, portanto, que a capacidade inovativa 
seja considerado um fator chave para o desenvolvimento e o processo de catch-up das nações, já que os catch-ups de sucesso são "historicamente associados não meramente à adoção de técnicas existentes em indústria já bem estabelecidas, mas também à inovação, particularmente organizacional, impregnada em novas indústrias” (FAGERBERG, 2003).

Há, certamente, características institucionais, culturais e históricas próprias e únicas a cada país que influenciam suas firmas. Dosi (1988) classifica-as como variáveis não-mercadológicas, não econômicas, na definição das externalidades e nos "resultados não planejados" dos processos de mercado. Setores, firmas e até certas tecnologias criam interdependências “não comercializadas”, mas ainda assim fundamentais na mudança tecnológica. Tais trocas são influenciadas por diferentes contextos, ingredientes fundamentais para a inovação, a saber: (a) configurações específicas de países/ regiões/ firmas; (b) processo de organização descentralizado e "irreversível”; (c) fatores associados diretamente às diferentes oportunidades, restrições e estímulos impostos. Ainda quanto à diferenciação entre países, podemos levar em consideração a existência de paradigmas tecnológicos, que diferenciam o progresso técnico "normal” do "extraordinário", relacionando o avanço do conhecimento ao ambiente no qual os agentes estão inseridos e diferindo países de acordo com suas capacidades, com papel direto de fatores institucionais e de um processo de pesquisa e seleção de paradigmas afetado pelas políticas públicas e pelo contexto científico, como a qualidade do link entre ciência e desenvolvimento técnico ; critérios e capacidade de pesquisa; restrições, incentivos e incertezas (DOSI, 1988).

Os trabalhos recentes para o caso brasileiro apontam, além dos conhecidos baixos níveis de produção de inovação das firmas nacionais, para um problema relacionado às "oportunidades e estímulos”, como descrito por Dosi: a efetividade de políticas públicas de incentivo à inovação. Indicadores construídos com dados de inovação de firmas e de setores industriais brasileiros sugerem que o que chamamos de "inovação" no Brasil está muito mais ligado à aquisição de máquinas, equipamentos e outros conhecimentos do que propriamente a processos de P\&D e criação de conhecimento. ${ }^{29}$

As políticas de inovação no Brasil, por sua vez, não parecem estar surtindo efeito no sentido de contornar o panorama de aprendizado passivo ${ }^{30}$. A vasta oferta de recursos destinados a atividades inovativas e de pesquisa e desenvolvimento parece não ter demanda qualificada à altura e, além disso, empresas que fazem uso destes recursos parecem ser as mesmas com tradição em atividades de $\mathrm{P} \& \mathrm{D}$, ou seja, os recursos de políticas de incentivo a programas de inovação parecem estar sendo destinados a empresas que os desenvolveriam de qualquer maneira, mas têm no governo uma fonte mais barata de recursos que reduz os riscos dos tradicionalmente altos investimentos em esforços desse tipo. Ainda, dados os indícios encontrados na literatura, políticas de inovação parecem estar financiando não a produção interna de conhecimento, mas os gastos com atividades inovativas que estão ligados à absorção de tecnologias e não à produção de inovações (MELO et al., 2015; ROCHA, 2015).

Os dados da PINTEC fornecem subsídio para sustentar esta tese. No setor de Informática do Brasil em 2010, por exemplo, 60\% das empresas foram classificadas como inovadoras, mas destes 60\%, apenas $1,5 \%$ implementaram inovações de produto e $1 \%$ de processo para o mercado mundial. Destes mesmos $60 \%$, o percentual de empresas que inovaram em produto sem distinção de grau de novidade sobe para $77,3 \%$, e em processo, $82 \%$. Ou seja, o que chamamos de inovação, tal como sugerido pelo próprio Manual de Oslo ${ }^{31}$ não passa de, na mais otimista das hipóteses, difusão tecnológica. Seguindo as próprias definições do Manual de Oslo, 76\% das empresas inovadoras em produto e $81 \%$ das inovadoras em processo não inovaram no sentido forte do conceito mas, sim, foram veículos de difusão tecnológica. Assim, será que temos de fato $60 \%$ de inovadoras entre as empresas de informática brasileiras? Se considerarmos gastos com maquinários, consultorias, treinamentos e serviços diversos como insuficientes para caracterizar uma empresa como inovativa no sentido mais estrito, a resposta é não. Abordada a questão pelo lado do esforço inovativo, temos que No mesmo setor de Informática supracitado, 3,5\% da

\footnotetext{
29 Tais como Melo, Fucidji e Possas (2015), Rocha (2015), Caria Junior (2015).

${ }^{30}$ Importação e aquisição de conhecimento, máquinas, técnicas e treinamento, em vez da criação do conhecimento.

31 Ver Caria Junior (2015, p.112-114).
} 
Receita Líquida de Vendas das empresas são direcionados às chamadas “Atividades Inovativas” 32 , percentual esse de 8,5\% nas empresas alemãs. No entanto, 92\% das empresas de informática alemãs realizaram alguma atividade de Pesquisa e Desenvolvimento até 2010, enquanto apenas 30\% das empresas brasileiras fizeram o mesmo. As empresas alemãs do setor direcionaram proporcionalmente cinco vezes mais recursos às atividades de $P \& D$ e empregaram quatro vezes mais pessoal especializado em pesquisa. No setor de produtos químicos, o gasto brasileiro em atividades inovativas como proporção da receita líquida foi de 2,3\% contra 3,2\% das alemãs. Esse indicador, sozinho, não apontaria grandes diferenças entre a qualidade dos investimentos de Brasil e Alemanha, não fossem os demais indicadores que compõem a dimensão de Esforço Inovativo proposta neste trabalho: 86\% das empresas alemãs do setor desenvolveram atividades de $\mathrm{P} \& \mathrm{D}$ ante $26 \%$ das brasileiras, $71 \%$ das empresas inovativas mantiveram programas contínuos de Pesquisa e Desenvolvimento contra 35\% das brasileiras, empregaram duas vezes mais de suas receitas em atividades específicas de $P \& D$ e empregaram três vezes mais pessoal especializado neste tipo de atividade. (CARIA JUNIOR, 2015).

Estes dois setores são apenas exemplos de uma dinâmica vista em Rocha (2015) e Melo et al (2015) e que aponta na mesma direção: os gastos que classificam as empresas brasileiras como “inovativas” não são gastos que conduzem à criação de inovações em sentido estrito, que conferem ganhos financeiros superiores, vantagens competitivas e consequente competividade. $\mathrm{O}$ elevado grau de gastos em Atividades Inovativas sem contrapartida em indicadores de P\&D e de implementação de inovações de facto revela um caráter majoritariamente passivo da atividade inovativa brasileira, que parece focada em gastos para a aquisição de tecnologias e conhecimento em detrimento da produção interna destes.

\section{Referências Bibliográficas}

\footnotetext{
32 Segundo o Manual de Oslo, atividade inovativas podem ser "executadas dentro da empresa ou podem envolver a aquisição de bens, serviços ou conhecimento de fontes externas, inclusive de serviços de consultoria. Assim, a empresa pode adquirir tecnologia externa de forma corpórea ou incorpórea.” (2004, p. 66)
} 
ABRAMOVITZ, M. Catching up, forging ahead, and falling behind. Journal of Economic History, v. 66, n. 2, p. 385-406, jun. 1986.

ALVES, P.; DE NEGRI, J. Mapeamento das Grandes Firmas que Investem em P\&D na Indústria Brasileira. 2009

AMABLE, B. VERSPAGEN, B.; The role of technology in market shares dynamics, Applied Economics, 27, 197-204. 1995.

AMENDOLA, G.; DOSI, G.; PAPAGNI, E. The dynamics of industrial competitiveness. Weltwirtschaftliches Archiv, v. 129, n. 3, p. 451-471, set.1993.

AREND, M. FONSECA, P.C.D. Brasil (1955-2005): 25 anos de catching up, 25 anos de falling behind. Revista de Economia Política, vol. 32, pp. 33-54, jan-mar 2012.

AVELLAR, A. P. Políticas de inovação no Brasil: uma análise com base na PINTEC 2008. Economia \& Tecnologia, ano 6, v. 23, p. 139-149, out./dez. 2010.

BELL, M.; PAVITT, K. Technological accumulation and industrial growth: contrasts between developed and developing countries. Industrial and Corporate Change, v. 2, n. 2, p. 157-210, 1993.

CAMPOS, B. C. Aspectos da padronização setorial das inovações na indústria Brasileira: uma análise multivariada a partir da pintec 2000. In: CONGRESSO DA ANPEC. Anais. 2005

CAMPOS, B.; RUIZ, A. U. Padrões setoriais de inovação na indústria brasileira. Revista Brasileira de Inovação, v. 8, n. 1 jan/jun, p. 167-210, 2009.

CARIA JUNIOR, S. Hiato Tecnológico e Catching-up - uma abordagem a partir da inovação. Dissertação de Mestrado. Universidade Estadual Paulista “Júlio de Mesquita Filho”. Araraquara, 2015.

CASSIOLATO, J. E.; LASTRES, M. H. Inovação, globalização e as novas políticas de desenvolvimento industrial e tecnológico. Nota Técnica 21/98. Projeto Globalização e inovação localizada: experiências de sistemas locais no âmbito do Mercosul e proposições de políticas de ciência e tecnologia. Rio de Janeiro, novembro de 1998.

CASSIOLATO, J.E.; LASTRES, H.M.M.; MACIEL, M.L. (Ed.). Systems of innovation and development: evidence from Brazil. Cheltenham: Edward Elgar, 2003.

COUTINHO, L.; FERRAZ, J.C. Estudo da competitividade da indústria brasileira. Síntese final. Campinas: FUCAMP, Universidade Estadual de Campinas, São Paulo: Papirus, 1994.

DE NEGRI, F. Empresas estrangeiras na indústria brasileira: características e impactos sobre o comércio exterior. In: LAPLANE, M., COUTINHO, L., HIRATUKA, C. orgs.). Internacionalização e desenvolvimento da indústria no Brasil. São Paulo: Editora Unesp, 2003.

Padrões tecnológicos e de comércio exterior das firmas brasileiras. In: DE NEGRI, J. A.; SALERNO, M. S. (org.), Inovações, padrões tecnológicos e desempenho das firmas industriais brasileiras. Brasília: IPEA, 2005.

DE NEGRI, J. A.; SALERNO, M. S.; DE CASTRO, A. B. . Inovações, padrões tecnológicos e desempenho das firmas industriais brasileiras. In: DE NEGRI, J. A.; SALERNO, M. S. (org.), Inovações, padrões tecnológicos e desempenho das firmas industriais brasileiras. Brasília: IPEA, 2005.

DOSI, G., FREEMAN, C., NELSON, R.R., SILVERBERG, G., and SOETE, L. (eds.). Technical Change and Economic Theory, Pinter, London, 1988.

DOSI, G., PAVITT, K. SOETE, L.G. The Economics of Technical Change and International Trade, London: Harvester Wheatsheaf, 1990. 
DOSI, G.; SOETE, L. Technology gaps and cost-based adjustment: some explorations on the determinants of international competitiveness. Metroeconomica, v. 35, n. 3, p. 197-222, out. 1983.

ERBER, F. S. O padrão de desenvolvimento industrial e tecnológico e o futuro da indústria brasileira. Revista de Economia Contemporânea, v. 5, n. especial, p. 179-206, 2001.

Inovação tecnológica na indústria brasileira no passado recente: uma resenha da literatura econômica; Textos para Discussão CEPAL-IPEA,17; DF; CEPAL, Escritório no Brasil/IPEA, 2010.

FAGERBERG, J. Innovation: A Guide to the Literature. in Fagerberg, J., D. C. Mowery and R. R. Nelson (eds) Oxford Handbook of Innovation, Oxford: Oxford University Press, 2004.

Publishers, 1994.

Why growth rates differ. Technical change and economic theory. London: Pinters

FAGERBERG, J., FOSAAS, M. and SAPPRASERT, K. Innovation: Exploring the knowledge base, Research Policy, 2012.

FAGERBERG, J., GODINHO, M. M. Innovation and Catching-up. in Fagerberg, J., Mowery, D., Nelson, R. (eds.), The Oxford Handbook of Innovation, Oxford: Oxford University Press, 2004.

FAGERBERG, J., MARTIN, B. and ANDERSEN, E.S. Innovation Studies: Evolution and Future Challenges, Oxford: Oxford University Press, 2013.

FERRAZ, J. C., KUPFER, D., HAGUENAUER, L. Made in Brazil: desafios competitivos para a indústria brasileira. Rio de Janeiro: Campus, 1995.

FREEEMAN, C. SOETE, L. The Economics of Industrial Innovation. The MIT Press, 1997.

FROHLICH, C.E. NAKABASHI, L. O hiato tecnológico entre a economia brasileira e a norte-americana no período 1982-2003: evidências empíricas. Economia \& Tecnologia, vol. 20, jan-mar 2010.

FURTADO, A. T., CARVALHO, R. de Q. Padrões de intensidade tecnológica da indústria brasileira: um estudo comparativo com os países centrais. São Paulo em Perspectiva, São Paulo, v. 19, n. 1, p. 70-84, mar., 2005.

FURTADO, A.; QUADROS, R. Construindo o IBI. Inovação Uniemp, v. 2, n. 3, p. 26-27, 2006.

GERSCHENKRON, A. Economic backwardness in historical perspective: a book of essays. Cambridge, Mass: Belknap, 1962.

GODIN, B. The Linear Model of Innovation: The Historical Construction of an Analytic Framework", Science, Technology \& Human Values 31 (6), 2006.

GROSSMAN, G.M. e HELPMAN, E. (1994) 'Technology and Trade’, NBER Working Paper n’ 4926.

HIGACHI, H. CANUTO, O. PORCILE, G. Modelos evolucionistas de crescimento endógeno. Revista de Economia Política, vol. 19, out-nov 1999.

KANNEBLEY Jr., S., PORTO, G. S., PAZZELO, E. T. Características das empresas inovadoras no Brasil: uma análise empírica a partir da Pintec. Anais do XXXI Encontro Nacional de Economia, Porto Seguro, Anpec, 2003.

exploratória a partir da PINTEC”, Revista Brasileira de Inovação, v.3, n.1, p.87-128, 2004.

KANNEBLEY S. Jr., "Características das Firmas Inovadoras no Estado de São Paulo: Uma Análise Empírica a partir da PAEP”. Texto para Discussão FEA-RP/USP, Série Economia, n.40-2003. 
MELO, T.M. FUCIDJI, J.R. POSSAS, M.L. Política industrial como política de inovação: notas sobre hiato tecnológico, políticas, recursos e atividades inovativas no Brasil. Revista Brasileira de Inovação. Vol. 14, Número Especial - Política Industrial e Inovação. UNICAMP: São Paulo, 2015.

NELSON, R.R. Research on Productivity Growth and Productivity Differences: Dead Ends and New Departures. Journal of Economic Literature. 1981.

. What Has Been the Matter with Neoclassical Growth Theory? Conferência “Convergência e Divergência em Crescimento Econômico e Mudança Tecnológica”. Maastrict, 1992.

NELSON, R.R. WRIGHT, G. The rise and fall of American technological leadership: the postwar era in historical perspective. Journal of Economic Literature. 1992.

NELSON, R.R., WINTER, S.G. An evolutionary theory of economic change, Cambridge: Belknap Press, 1982.

OCDE. Manual de Oslo: Diretrizes para a Coleta e Interpretação de Dados sobre Inovação. $3^{a}$ edição. Rio de Janeiro: FINEP, 2004.

OHKAWA, K. ROSOVSKY, H. Japanese economic growth. Stanford: Stanford U. Press, 1973.4

PAVITT, K. Sectoral patterns of technical change: towards a taxonomy and a theory. Research Policy, v. 13, n. 4, p. 343-373, 1984.

PAVITT, K. SOETE, L.G. International Differences in Economic Growth and the International Location of Innovation. Em: Emerging technologies: Consequences for economic growth, structural change and employment. Herbert Giersch. Tubingen: JCB Mohr, 1982.

PENROSE, E.T. The Theory of the Growth of the Firm. New York: John Wiley \& Sons, Inc. 1959.

PEREIRA, A.J. Teoria da firma e analogias biológicas: em busca de uma contribuição teórica para o estudo das empresas transnacionais como agentes da transformação econômica. Anais do encontro de economia da região sul. PUC-RS, Rio Grande do Sul, 2012.

POSNER, M. V. International trade and technical change. Oxford Economic Papers, v. 13, n. 3, p. 323341, out. 1961.

POSSAS , M.L Elementos para uma integração micro-macrodinâmica na teoria do desenvolvimento econômico. Revista Brasileira de Inovação, v.1, n.1, 2002.

. "Eficiência Seletiva: uma Perspectiva Neo-Schumpeteriana Evolucionária sobre Questões Econômicas Normativas". In: Proceedings do Seminário "Frontiers and Trends of Development: Innovation Research and Policy”, IE/UFRJ e CRIC/Univ. of Manchester, Rio de Janeiro, 25-26.09.2002.

Competitividade: fatores sistêmicos e política industrial: implicações para o Brasil.

In: CASTRO, A. B.; POSSAS, M. L.; PROENÇA, A. (Orgs.). Estratégias empresariais na indústria brasileira: discutindo mudanças. Rio de Janeiro: Forense Universitária, 1996.

- Eficiência Seletiva: uma Perspectiva Neo-Schumpeteriana Evolucionária sobre Questões Econômicas Normativas. Revista de Economia Política, São Paulo, v. 24, n. 1, p. 73-94, jan.mar. 2004.

POSSAS, M. S. Concorrência e competitividade: notas sobre estratégia e dinâmica seletiva na economia capitalista. São Paulo: Hucitec, 1999.

POSSAS, M.; DWECK, E. A multisectoral micro-macrodynamic model. Economia, ANPEC, v.5, n.3, 2004. Selecta do XXXII Encontro Nacional de Economia. João Pessoa, PB, dezembro 2004. 
ROCHA, C.F.L. Does Governmental support for innovation have positive effect on R\&D investments? Evidence from Brazil. Política industrial como política de inovação: notas sobre hiato tecnológico, políticas, recursos e atividades inovativas no Brasil. Revista Brasileira de Inovação. Vol. 14, Número Especial - Política Industrial e Inovação. UNICAMP: São Paulo, 2015.

ROCHA, F., KUPFER, D. Structural changes and specialization inBrazil industry: the evolution of leading companies and the M\&A process. The Developing Economies, v. 3, n. 40, Dec.2002.

ROMER, P.M. Endogenous Technological Change. Journal of Political Economy, 1990.

What determines the Rate of Growth and Technological Change? Working Papers, Macroeconomic Adjustment and Growth, Country Economics Department, WPS 279. Washington DC: The World Bank, 1989.

ROSENBERG, N. How Exogenous is Science?. In: Inside the Black Box:Technology and Economics. Cambridge: Cambridge University Press, 1982.

SBRAGIA, R.; KRUGLIANSKAS, I.; ARANGO-ALZATE, T. Empresas inovadoras no Brasil: uma proposição de tipologia e características associadas”, FEA/USP: Série Working Papers, n.001/003, 2002.

SCHUMPETER, J. A. Capitalism, Socialism and Democracy, New York: Harper, 1942.

Press, 1934. . The Theory of Economic Development, Cambridge, Mass: Harvard University

URRACA, A. Persistência versus mudança estrutural da especialização tecnológica do Brasil. Economia e Sociedade, v. 17, 2008.

VIOTTI, E. BAESSA, A. KOELLER, P. Perfil da inovação na indústria brasileira: uma comparação internacional. In: De Negri, J. Salerno, M. (Org.). Inovações, padrões tecnológicos e desempenho das firmas industriais brasileiras. Brasília: Ipea, 2005. 